\title{
Cutaneous Manifestations of COVID-19: Characteristics, Pathogenesis, and the Role of Dermatology in the Pandemic
}

\author{
Mariam Alam, MD; William Lewis, MD; Joanna Harp, MD; Katherine Steele, MD;
}

Misha Rosenbach, MD; Robert G. Micheletti, MD

\section{PRACTICE POINTS}

- Cutaneous manifestations of COVID-19 may reflect the range of host immunologic responses to SARS-CoV-2.

- Perniosis appears to be a late manifestation of COVID-19 associated with a comparatively benign disease course, whereas livedoid or other vasculopathic lesions portend poorer outcomes and may warrant further workup for occult thrombotic disease.

- Maculopapular, vesicular, and urticarial eruptions may be seen in association with COVID-19 but are nonspecific and necessitate a broad differential and workup.

- Challenges posed by the COVID-19 pandemic necessitate creative management strategies for immunosuppression and clinical assessment.

Cutaneous manifestations of COVID-19-SARS-CoV-2-are common and varied. Morbilliform, vesicular, and urticarial eruptions may be nonspecific initial features of the disease. Chilblainlike lesions on the fingers or toes typically occur as part of a resolution phase, signifying a milder course, whereas livedoid lesions and retiform purpura are associated with coaguloapthy and more severe disease. Additionally, a severe Kawasaki-like multisystem inflammatory syndrome rarely is seen in children. This diverse range of cutaneous manifestations in COVID-19 reflects a spectrum of host immunologic responses to SARS-CoV-2 and may inform disease pathophysiology. Cutis. 2021;107:209-215.
The virus that causes COVID-19-SARS-CoV-2has infected more than 128 million individuals, resulting in more than 2.8 million deaths worldwide between December 2019 and April 2021. Disease mortality primarily is driven by hypoxemic respiratory failure and systemic hypercoagulability, resulting in multisystem organ failure. ${ }^{1}$ With more than 17 million Americans infected, the virus is estimated to have impacted someone within the social circle of nearly every American. ${ }^{2}$

The COVID-19 pandemic has highlighted resource limitations, delayed elective and preventive care, and rapidly increased the adoption of telemedicine, presenting a host of new challenges to providers in every medical specialty, including dermatology. Although COVID-19 primarily is a respiratory disease, clinical manifestations have been observed in nearly every organ, including the skin. The cutaneous manifestations of COVID-19 provide insight into disease diagnosis, prognosis, and pathophysiology. In this article, we review the cutaneous manifestations of COVID-19 and explore the state of knowledge regarding their pathophysiology and clinical significance. Finally, we discuss the role of dermatology consultants in the care of patients with COVID-19, and the impact of the pandemic on the field of dermatology.

\section{Prevalence of Cutaneous Findings in COVID-19}

Early reports characterizing the clinical presentation of patients hospitalized with COVID-19 suggested skin findings associated with the disease were rare. Cohort studies from Europe, China, and New York City in January through March 2020 reported a low prevalence or made no mention

Drs. Alam, Lewis, Steele, Rosenbach, and Micheletti are from the Department of Dermatology, University of Pennsylvania, Philadelphia. Dr. Harp is from New York-Presbyterian/Weill Cornell Medical Center, New York.

The authors report no conflict of interest.

Correspondence: Robert G. Micheletti, MD, 3400 Civic Center Blvd, 7 South PCAM, Room 724, Philadelphia, PA 19104

(Robert.micheletti@pennmedicine.upenn.edu).

doi:10.12788/cutis.0230 
of rash. ${ }^{3-7}$ However, reports from dermatologists in Italy that emerged in May 2020 indicated a substantially higher proportion of cutaneous disease: 18 of 88 (20.4\%) hospitalized patients were found to have cutaneous involvement, primarily consisting of erythematous rash, along with some cases of urticarial and vesicular lesions. ${ }^{8}$ In October 2020, a retrospective cohort study from Spain examining 2761 patients presenting to the emergency department or admitted to the hospital for COVID-19 found that $58(2.1 \%)$ patients had skin lesions attributed to COVID-19. ${ }^{9}$

The wide range in reported prevalence of skin lesions may be due to variable involvement of dermatologic specialists in patient care, particularly in China. ${ }^{10}$ Some variation also may be due to variability in the timing of clinical examination, as well as demographic and clinical differences in patient populations. Of note, a multisystem inflammatory disease seen in US children subsequent to infection with COVID-19 has been associated with rash in as many as $74 \%$ of cases. ${ }^{11}$ Although COVID-19 disproportionately impacts people with skin of color, there are few reports of cutaneous manifestations in that population, ${ }^{12}$ highlighting the challenges of the dermatologic examination in individuals with darker skin and suggesting the prevalence of dermatologic disease in COVID-19 may be greater than reported.

\section{Morphologic Patterns of Cutaneous Involvement in COVID-19}

Researchers in Europe and the United States have attempted to classify the cutaneous manifestations of COVID-19. A registry established through the American Academy of Dermatology published a compilation of reports from 31 countries, totaling 716 patient profiles. ${ }^{13}$ A prospective Spanish study detailed the cutaneous involvement of 375 patients with suspected or confirmed COVID-19. ${ }^{14}$ Together, these efforts have revealed several distinct patterns of cutaneous involvement associated with COVID-19 (Table). ${ }^{9,15-18}$

Vesicular Rash-Vesicular rash associated with COVID-19 has been described in several studies and case series $^{8,13,14}$ and is considered, along with the pseudopernio (or pseudochilblains) morphology, to be one of the more disease-specific patterns in COVID-19. ${ }^{14,18}$ Vesicular rash appears to comprise roughly one-tenth of all COVID-19-associated rashes. ${ }^{13,14}$ It usually is described as pruritic, with $72 \%$ to $83 \%$ of patients reporting itch. ${ }^{13,16}$

Small monomorphic or polymorphic vesicles predominantly on the trunk and to a lesser extent the extremities and head have been described by multiple authors. ${ }^{14,16}$ Vesicular rash is most common among middle-aged

\section{Cutaneous Manifestations of COVID-19}

\begin{tabular}{|c|c|c|c|c|}
\hline $\begin{array}{l}\text { Cutaneous } \\
\text { finding }\end{array}$ & $\begin{array}{l}\text { Typical patient } \\
\text { demographic }\end{array}$ & Typical timing of onset & Distinguishing features & $\begin{array}{l}\text { Prognostic } \\
\text { significance or } \\
\text { associations }\end{array}$ \\
\hline $\begin{array}{l}\text { Vesicular } \\
\text { eruption }\end{array}$ & Middle-aged patients & $\begin{array}{l}\text { Concurrent with or after other } \\
\text { symptoms }\end{array}$ & $\begin{array}{l}\text { Pruritic, predominantly truncal; } \\
\text { can be monomorphic or } \\
\text { polymorphic }\end{array}$ & Moderate disease \\
\hline $\begin{array}{l}\text { Urticarial } \\
\text { eruption }\end{array}$ & Middle-aged patients & After other symptoms & Pruritic, predominantly truncal & $\begin{array}{l}\text { Moderate disease, } \\
\text { polypharmacy }\end{array}$ \\
\hline $\begin{array}{l}\text { Morbilliform } \\
\text { eruption }\end{array}$ & Middle-aged patients & After other symptoms & $\begin{array}{l}\text { Heterogeneous; erythema } \\
\text { multiforme-like, pseudovesicular, } \\
\text { or erythema elevatum diutinum- } \\
\text { like morphologies may be more } \\
\text { specific for COVID-19 }\end{array}$ & $\begin{array}{l}\text { Moderate to } \\
\text { severe disease, } \\
\text { polypharmacy }\end{array}$ \\
\hline Perniolike rash & Younger patients & $\begin{array}{l}\text { In resolution phase of illness } \\
\text { or as an initial isolated finding } \\
\text { in otherwise asymptomatic } \\
\text { patients }\end{array}$ & $\begin{array}{l}\text { Painful, pruritic, violaceous } \\
\text { erythema, most commonly on } \\
\text { the toes }\end{array}$ & $\begin{array}{l}\text { Asymptomatic or } \\
\text { mild disease }\end{array}$ \\
\hline $\begin{array}{l}\text { Livedoid } \\
\text { rash/retiform } \\
\text { purpura }\end{array}$ & Elderly patients & After other symptoms & $\begin{array}{l}\text { Netlike purpuric or violaceous } \\
\text { patches }\end{array}$ & $\begin{array}{l}\text { Severe disease or } \\
\text { critical illness }\end{array}$ \\
\hline $\begin{array}{l}\text { MIS-C } \\
\text { associated }\end{array}$ & $\begin{array}{l}\text { Young children and } \\
\text { adolescents }\end{array}$ & $\begin{array}{l}\text { After other symptoms, } 2-4 \\
\text { wk postinfection }\end{array}$ & $\begin{array}{l}\text { Palmoplantar erythema, } \\
\text { periorbital erythema and edema, } \\
\text { lip hyperemia, malar erythema, } \\
\text { strawberry tongue, conjunctival } \\
\text { injection }\end{array}$ & $\begin{array}{l}\text { Severe multisystem } \\
\text { illness, cardiac } \\
\text { dysfunction, } \\
\text { coagulopathy, and } \\
\text { gastrointestinal } \\
\text { illness }\end{array}$ \\
\hline
\end{tabular}

Abbreviation: MIS-C, multisystem inflammatory syndrome in children. 
individuals, with studies reporting median and mean ages ranging from 40.5 to 55 years. $9,13,14,16$

Vesicular rash develops concurrent with or after other presenting symptoms of COVID-19; in 2 studies, vesicular rash preceded development of other symptoms in only $15 \%$ and $5.6 \%$ of cases, respectively. ${ }^{13,14}$ Prognostically, vesicular rash is associated with moderate disease severity. ${ }^{14,16}$ It may persist for an average of 8 to 10 days. ${ }^{14,16,18}$

Histopathologic examination reveals basal layer vacuolar degeneration, hyperchromatic keratinocytes, acantholysis, and dyskeratosis. ${ }^{9,16,18}$

Urticarial Rash-Urticarial lesions represent approximately $7 \%$ to $19 \%$ of reported COVID-19-associated rashes. ${ }^{9,13,14}$ Urticarial rashes in patients testing positive for SARS-CoV-2 primarily occur on the trunk..$^{14}$ The urticaria, which typically last about 1 week, ${ }^{14}$ are seen most frequently in middle-aged patients (mean/median age, $42-48$ years) ${ }^{13,14}$ and are associated with pruritus, which has been reported in $74 \%$ to $92 \%$ of patients. ${ }^{13,14}$ Urticarial lesions typically do not precede other symptoms of COVID-19 and are nonspecific, making them less useful diagnostically. ${ }^{14}$

Urticaria appears to be associated with more severe COVID-19 illness in several studies, but this finding may be confounded by several factors, including older age, increased tobacco use, and polypharmacy. Of 104 patients with reported urticarial rash and suspected or confirmed COVID-19 across 3 studies, only 1 death was reported.9,13,14

The histopathologic appearance is that of typical hives, demonstrating a perivascular infiltrate of lymphocytes and eosinophils with edema of the upper dermis.

Morbilliform Eruption-Morbilliform eruption is a commonly reported morphology associated with COVID-19, accounting for $20 \%$ to $47 \%$ of rashes. $9,13,14$ This categorization may have limited utility from a diagnostic and prognostic perspective, given that morbilliform eruptions are common, nonspecific, and heterogenous and can arise from many causes., 13,14 Onset of morbilliform eruption appears to coincide with ${ }^{14}$ or follow ${ }^{13,20,21}$ the development of other COVID-19-related symptoms, with $5 \%$ of patients reporting morbilliform rash as the initial manifestation of infection. ${ }^{13,14}$ Morbilliform eruptions have been observed to occur in patients with more severe disease. ${ }^{9,13,14}$

Certain morphologic subtypes, such as erythema multiforme-like, erythema elevatum diutinum-like, or pseudovesicular, may be more specific to COVID-19 infection. ${ }^{14} \mathrm{~A}$ small case series highlighted 4 patients with erythema multiforme-like eruptions, 3 of whom also were found to have petechial enanthem occurring after COVID-19 diagnosis; however, the investigators were unable to exclude drug reaction as a potential cause of rash in these patients..$^{22}$ Another case series of 21 patients with COVID-19 and skin rash described a (primarily) petechial enanthem on the palate in $6(28.5 \%)$ patients. ${ }^{23}$ It is unclear to what extent oral enanthem may be underrecognized given that some physicians may be disinclined to remove the masks of known COVID-19-positive patients to examine the oral cavity.
The histologic appearance of morbilliform rash seen in association with COVID-19 has been described as spongiotic with interface dermatitis with perivascular lymphocytic inflammation. ${ }^{9,21}$

COVID Toes, Pseudochilblains Rash, Perniolike Rash, and Acral Erythema/Edema-Of all the rashes associated with COVID-19, COVID toes, or pseudochilblains rash, has perhaps attracted the most attention. The characteristic violaceous erythema on the fingers and/or toes may be itchy or painful, presenting similar to idiopathic cases of pernio (Figure 1). ${ }^{14}$ The entity has been controversial because of an absence of a clear correlation with a positive SARS-CoV-2 polymerase chain reaction test or antibodies to the virus in a subset of reported cases. ${ }^{24,25}$ Onset of the rash late in the disease course, generally after symptom resolution in mild or asymptomatic cases, may explain the absence of viral DNA in the nasopharynx by the time of lesion appearance. ${ }^{14,26}$ Seronegative patients may have cleared SARS-CoV-2 infection before humoral immunity could occur via a strong type 1 interferon response. ${ }^{25}$

Across 3 studies, perniolike skin lesions constituted $18 \%$ to $29 \%$ of COVID-19-associated skin findings $9,13,14$ and persisted for an average of 12 to 14 days. ${ }^{13,14}$ Perniolike lesions portend a favorable outcome; patients with COVID toes rarely present with systemic symptoms or laboratory or imaging abnormalities ${ }^{9}$ and less commonly require hospitalization for severe illness. Perniolike lesions have been reported most frequently in younger patients, with a median or mean age of 32 to 35 years. ${ }^{13,14}$

Histology demonstrates lichenoid dermatitis with perivascular and periadnexal lymphocytic infiltrates. ${ }^{9}$ Notably, one study observed interface dermatitis of the intraepidermal portion of the acrosyringium, a rare finding in chilblain lupus, in $83 \%$ of patients $(\mathrm{N}=40) .{ }^{25}$ Direct immunofluorescence demonstrates a vasculopathic pattern, with some patients showing deposition of IgM or

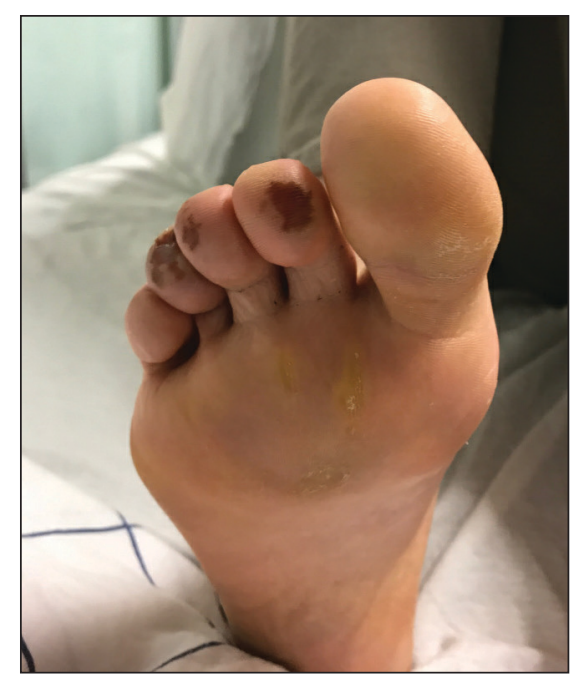

FIGURE 1. COVID toes/pseudochillblains rash. 
IgG, C3, and fibrinogen in dermal blood vessels. Vascular C9 deposits also have been demonstrated on immunohistochemistry. ${ }^{9}$ Biopsies of perniolike lesions in COVID-19 patients have demonstrated the presence of SARS-CoV-2 $\mathrm{RNA}^{27}$ have identified SARS-CoV-2 spike protein in endothelial cells on immunohistochemistry, and have visualized intracytoplasmic viral particles in vascular endothelium on electron microscopy. ${ }^{28}$

Livedoid Rash/Retiform Purpura-Netlike purpuric or violaceous patches signifying vessel damage or occlusion have been seen in association with COVID-19, constituting approximately $6 \%$ of COVID-19-associated skin findings in 2 studies. ${ }^{13,14}$ Livedoid rash (Figure 2) and retiform purpura (Figure 3) are associated with older age and occur primarily in severely ill patients, including those requiring intensive care. In a registry of 716 patients with COVID-19, 100\% of patients with retiform purpura were hospitalized, and $82 \%$ had acute respiratory distress syndrome. ${ }^{13}$ In another study, $33 \%(7 / 21)$ of patients with livedoid and necrotic lesions required intensive care, and 10\% (2/21) died. ${ }^{14}$

Livedoid lesions and retiform purpura represent thrombotic disease in the skin due to vasculopathy/ coagulopathy. Dermatopathology available through the American Academy of Dermatology registry revealed thrombotic vasculopathy. ${ }^{13} \mathrm{~A}$ case series of 4 patients with

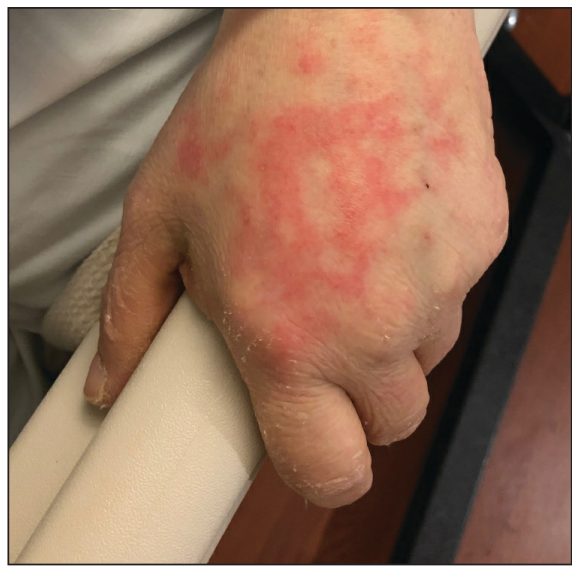

FIGURE 2. Fixed livedo reticularis associated with COVID-19.

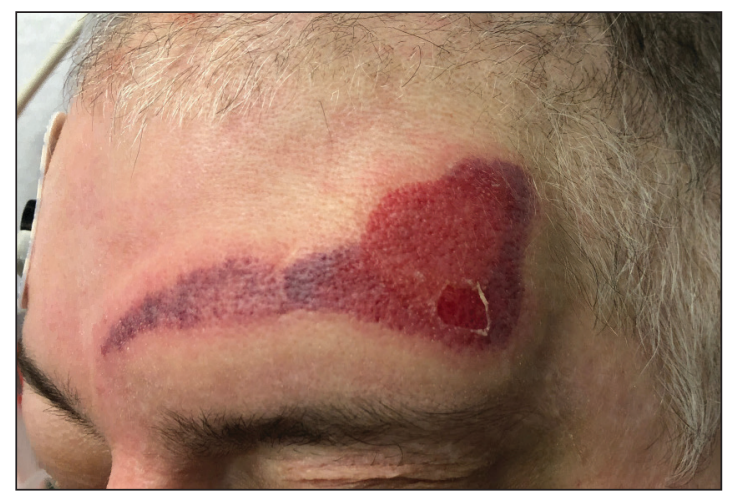

FIGURE 3. Retiform purpura associated with COVID-19. livedo racemosa and retiform purpura demonstrated pauciinflammatory thrombogenic vasculopathy involving capillaries, venules, and arterioles with complement deposition. ${ }^{29}$ Livedoid and retiform lesions in the skin may be associated with a COVID-19-induced coagulopathy, a propensity for systemic clotting including pulmonary embolism, which mostly occurs in hospitalized patients with severe illness. ${ }^{30}$

\section{Multisystem Inflammatory Disease in Children}

A hyperinflammatory syndrome similar to Kawasaki disease and toxic shock syndrome associated with mucocutaneous, cardiac, and gastrointestinal manifestations has been reported following COVID-19 infection. ${ }^{31}$ This syndrome, known as multisystem inflammatory syndrome in children (MIS-C), predominantly affects adolescents and children older than 5 years, ${ }^{11}$ typically occurs 2 to 4 weeks after infection, and appears to be at least 100-times less common than COVID-19 infection among the same age group. ${ }^{31}$ Sixty percent ${ }^{31}$ to $74 \%{ }^{11}$ of affected patients have mucocutaneous involvement, with the most common clinical findings being conjunctival injection, palmoplantar erythema, lip hyperemia, periorbital erythema and edema, strawberry tongue, and malar erythema, respectively. ${ }^{32}$

Because this condition appears to reflect an immune response to the virus, the majority of cases demonstrate negative SARS-CoV-2 polymerase chain reaction and positive antibody testing. ${ }^{33}$ Although cutaneous findings are similar to those seen in Kawasaki disease, certain findings have been noted in MIS- $\mathrm{C}$ that are not typical of Kawasaki disease, including heliotrope rash-like periorbital edema and erythema as well as erythema infectiosum-like malar erythema and reticulated erythematous eruptions. ${ }^{32}$

The course of MIS- $\mathrm{C}$ can be severe; in one case series of patients presenting with MIS-C, 80\% (79/99) required intensive care unit admission, with $10 \%$ requiring mechanical ventilation and $2 \%$ of patients dying during admission. ${ }^{31}$ Cardiac dysfunction, coagulopathy, and gastrointestinal symptoms are common. ${ }^{11,31}$ It has been postulated that a superantigenlike region of the SARS-CoV-2 spike protein, similar to that of staphylococcal enterotoxin B, may underlie MIS-C and account for its similarities to toxic shock syndrome. ${ }^{34}$ Of note, a similar multisystem inflammatory syndrome associated with COVID-19 also has been described in adults, and it too may present with rash as a cardinal feature. ${ }^{35}$

\section{Pathophysiology of COVID-19: What the Skin May Reveal About the Disease}

The diverse range of cutaneous manifestations in COVID-19 reflects a spectrum of host immunologic responses to SARS-CoV-2 and may inform the pathophysiology of the disease as well as potential treatment modalities.

Host Response to SARS-CoV-2-The body's response to viral infection is 2-pronged, involving activation of cellular antiviral defenses mediated by type I and III interferons, as well as recruitment of leukocytes, mobilized by cytokines and chemokines. ${ }^{36,37}$ Infection with 
SARS-CoV-2 results in a unique inflammatory response characterized by suppression of interferons, juxtaposed with a rampant proinflammatory cytokine and chemokine response, reminiscent of a cytokine storm. Reflective of this imbalance, a study of 50 COVID-19 patients and 20 healthy controls found decreased natural killer cells and $\mathrm{CD}^{+} \mathrm{T}$ cells in COVID-19 patients, particularly severely or critically ill patients, with an increase in $B$ cells and monocytes. ${ }^{38}$ This distinctive immune imbalance positions SARS-CoV-2 to thrive in the absence of inhibitory interferon activity while submitting the host to the deleterious effects of a cytokine surge. ${ }^{36}$

Type I Interferons-The perniolike lesions associated with mild COVID-19 disease ${ }^{14}$ may represent a robust immune response via effective stimulation of type I interferons (IFN-1). Similar perniolike lesions are observed in Aicardi-Goutières syndrome ${ }^{37}$ and familial chilblain lupus, hereditary interferonopathies associated with mutations in the TREX1 (three prime repair exonuclease 1) gene and characterized by inappropriate upregulation of IFN-1,39 resulting in chilblains. It has been suggested that perniolike lesions in COVID-19 result from IFN-1 activation-a robust effective immunologic response to the virus. ${ }^{14,26,40}$

On the other end of the spectrum, patients with severe COVID-19 may have a blunted IFN-1 response and reduced IFN-1-stimulated gene expression. ${ }^{36,38}$ Notably, low IFN-1 response preceded clinical deterioration and was associated with increased risk for evolution to critical illness. ${ }^{38}$ Severe disease from COVID-19 also is more commonly observed in older patients and those with comorbidities, ${ }^{1}$ both of which are known factors associated with depressed IFN-1 function. ${ }^{38,41}$ Reflective of this disparate IFN-1 response, biopsies of COVID-19 perniosis have demonstrated striking expression of myxovirus resistance protein A (MXA), a marker for IFN-1 signaling in tissue, whereas its expression is absent in COVID-19 livedo/retiform purpura. ${ }^{27}$

Familial chilblain lupus may be effectively treated by the Janus kinase inhibitor baricitinib, ${ }^{39}$ which inhibits IFN-1 signaling. Baricitinib recently received emergency use authorization by the US Food and Drug Administration for treatment of severe COVID-19 pneumonia, ${ }^{42,43}$ hinting to disordered IFN-1 signaling in the COVID-19 pathophysiology.

The impaired IFN-1 response in COVID-19 patients may be due to a unique characteristic of SARS-CoV-2: its ORF3b gene is a potent IFN-1 antagonist. In a series of experiments comparing SARS-CoV-2 to the related virus severe acute respiratory disease coronavirus (which was responsible for an epidemic in 2002), Konno et $\mathrm{a}^{44}$ found that SARS-CoV-2 is more effectively able to downregulate host IFN-1, likely due to premature stop codons on ORF3b that produce a truncated version of the gene with amplified anti-IFN-1 activity.

Cytokine Storm and Coagulation Cascade-This dulled interferon response is juxtaposed with a surge of inflammatory chemokines and cytokines, including IL-6, IL-8,
IL-10, and tumor necrosis factor $\alpha$, impairing innate immunity and leading to end-organ damage. This inflammatory response is associated with the influx of innate immune cells, specifically neutrophils and monocytes, which likely contribute to lung injury in COVID-19 acute respiratory distress syndrome..$^{38}$ It also is thought to lead to downstream activation of coagulation, with a high incidence of thrombotic events observed in patients with severe COVID-19. ${ }^{1}$ In a retrospective study of 184 intensive care patients with COVID-19 receiving at least standard doses of thromboprophylaxis, venous thromboembolism occurred in $27 \%$ and arterial thrombotic events occurred in $3.7 \%{ }^{45}$

Livedo racemosa and retiform purpura are cutaneous markers of hypercoagulability, which indicate an increased risk for systemic clotting in COVID-19. A positive feedback loop between the complement and coagulation cascades appears to be important. ${ }^{13,14,29,46-48}$ In addition, a few studies have reported antiphospholipid antibody positivity in hospitalized COVID-19 patients..$^{49,50}$

The high incidence of coagulopathy in severe COVID-19 has prompted many institutions to develop aggressive prophylactic anticoagulation protocols. Elevation of proinflammatory cytokines and observation of terminal complement activation in the skin and other organs has led to therapeutic trials of IL-6 inhibitors such as tocilizumab, ${ }^{51}$ complement inhibitors such as eculizumab, and Janus kinase inhibitors such as ruxolitinib and baricitinib. ${ }^{42,48}$

COVID Long-Haulers-The long-term effects of immune dysregulation in COVID-19 patients remain to be seen. Viral triggering of autoimmune disease is a wellestablished phenomenon, seen in DRESS (drug reaction with eosinophilia and systemic symptoms) syndrome and other dermatologic diseases, raising the possibility that dermatologists will see a rising incidence of cutaneous autoimmune disease in the aftermath of the pandemic. Disordered interferon stimulation could lead to increased incidence of interferon-mediated disorders, such as sarcoidosis and other granulomatous diseases. Vasculitislike skin lesions could persist beyond the acute infectious period. Recent data from a registry of 990 COVID-19 cases from 39 countries suggest that COVID-19 perniolike lesions may persist as long as 150 days. ${ }^{52}$ In a time of many unknowns, these questions serve as a call to action for rigorous data collection, contribution to existing registries for dermatologic manifestations of COVID-19, and long-term follow-up of COVID-19 patients by the dermatology community.

\section{Pandemic Dermatology}

The pandemic has posed unprecedented challenges for patient care. The use of hydroxychloroquine as a popular but unproven treatment for COVID-19, ${ }^{53}$ particularly early in the pandemic, has resulted in drug shortages for patients with lupus and other autoimmune skin diseases. Meanwhile, the need for patients with complex dermatologic conditions to receive systemic immunosuppression 
has had to be balanced against the associated risks during a global pandemic. To help dermatologists navigate this dilemma, various subspecialty groups have issued guidelines, including the COVID-19 Task Force of the Medical Dermatology Society and Society of Dermatology Hospitalists, which recommends a stepwise approach to shared decision-making with the goal of minimizing both the risk for disease flare and that of infection. The use of systemic steroids and rituximab, as well as the dose of immunosuppression-particularly broad-acting immunosuppression-should be limited where permitted. ${ }^{54}$

Rapid adoption of telemedicine and remote monitoring strategies has enabled dermatologists to provide safe and timely care when in-person visits have not been possible, including for patients with confirmed or suspected COVID-19, as well as for hospitalized patients..$^{5-57}$ Use of telemedicine has facilitated preservation of personal protective equipment at a time when these important resources have been scarce. For patients with transportation or scheduling barriers, telemedicine has even expanded access to care.

However, this strategy cannot completely replace comprehensive in-person evaluation. Variability in video and photographic quality limits evaluation, while in-person physical examination can reveal subtle morphologic clues necessary for diagnosis. ${ }^{58}$ Additionally, unequal access to technology may disadvantage some patients. For dermatologists to provide optimal care and continue to contribute accurate and insightful observations into COVID-19, it is essential to be physically present in the clinic and in the hospital when necessary, caring for patients in need of dermatologic expertise. Creative management strategies developed during this time will benefit patients and expand the reach of the specialty. 58

\section{Final Thoughts}

The COVID-19 pandemic has profoundly challenged the medical community and dermatology is no exception. By documenting and characterizing the diverse cutaneous manifestations of this novel disease, dermatologists have furthered understanding of its pathophysiology and management. By adapting quickly and developing creative ways to deliver care, dermatologists have found ways to contribute, both large and small. As we take stock at this juncture of the pandemic, it is clear there remains much to learn. We hope dermatologists will continue to take an active role in meeting the challenges of this time.

\section{REFERENCES}

1. Wiersinga WJ, Rhodes A, Cheng AC, et al. Pathophysiology, transmission, diagnosis, and treatment of coronavirus disease 2019 (COVID-19): a review. JAMA. 2020;324:782-793. doi:10.1001/jama.2020.12839

2. Harmon A, Tompkins L, Burch ADS, et al. With 11 million cases in the U.S., the coronavirus has gotten personal for most people. New York Times. Updated December 23, 2020. Accessed March 22, 2021. https://www.nytimes.com/2020/11/15/us/coronavirus-us-cases-deaths.html

3. Guan W, Ni Z, Hu Y, et al. Clinical characteristics of coronavirus disease 2019 in China. N Engl J Med. 2020;382:1708-1720. doi:10.1056/NEJMoa2002032
4. Lechien JR, Chiesa-Estomba CM, Place S, et al. Clinical and epidemiological characteristics of 1420 European patients with mild-tomoderate coronavirus disease 2019. J Intern Med. 2020;288:335-344. doi:https://doi.org/10.1111/joim.13089

5. Wu J, Liu J, Zhao $X$, et al. Clinical characteristics of imported cases of coronavirus disease 2019 (COVID-19) in Jiangsu province: a multicenter descriptive study. Clin Infect Dis. 2020;71:706-712. doi:10.1093/ cid/ciaa199

6. Goyal P, Choi JJ, Pinheiro LC, et al. Clinical characteristics of COVID-19 in NewYork City. N Engl J Med. 2020;382:2372-2374. doi:10.1056/ NEJMc2010419

7. Sun L, Shen L, Fan J, et al. Clinical features of patients with coronavirus disease 2019 from a designated hospital in Beijing, China. J Med Virol. 2020;92:2055-2066. https://doi.org/10.1002/jmv.25966

8. Recalcati S. Cutaneous manifestations in COVID-19: a first perspective. J Eur Acad Dermatology Venereol. 2020;34:E212-E213. https://doi.org/10.1111/ jdv.16387

9. Giavedoni P, Podlipnik S, Pericàs JM, et al.Skin manifestations in COVID-19: prevalence and relationship with disease severity. J Clin Med. 2020;9:3261. doi:10.3390/jcm9103261

10. Jimenez-Cauhe J, Ortega-Quijano D, Prieto-Barrios M, et al. Reply to "COVID-19 can present with a rash and be mistaken for dengue": petechial rash in a patient with COVID-19 infection. J Am Acad Dermatol. 2020;83:E141-E142. doi:10.1016/j.jaad.2020.04.016

11. Feldstein LR, Rose EB, Horwitz SM, et al. Multisystem inflammatory syndrome in U.S. children and adolescents. N Engl J Med. 2020;383:334-346. doi:10.1056/NEJMoa2021680

12. Shinkai K, Bruckner AL. Dermatology and COVID-19. JAMA. 2020;324:1133-1134. doi:10.1001/jama.2020.15276

13. Freeman EE, McMahon DE, Lipoff JB, et al. The spectrum of COVID-19-associated dermatologic manifestations: an international registry of 716 patients from 31 countries. J Am Acad Dermatol. 2020; 83:1118-1129. doi:10.1016/j.jaad.2020.06.1016

14. Galván Casas C, Català A, Carretero Hernández G, et al. Classification of the cutaneous manifestations of COVID-19: a rapid prospective nationwide consensus study in Spain with 375 cases. Br J Dermatol. 2020;183:71-77. https://doi.org/10.1111/bjd.19163

15. Bouaziz JD, Duong TA, Jachiet M, et al. Vascular skin symptoms in COVID-19: a French observational study. J Eur Acad Dermatology Venereol. 2020;34:E451-E452. https://doi.org/10.1111/jdv.16544

16. Fernandez-Nieto D, Ortega-Quijano D, Jimenez-Cauhe J, et al. Clinical and histological characterization of vesicular COVID-19 rashes: a prospective study in a tertiary care hospital. Clin Exp Dermatol. 2020;45:872-875. https://doi.org/10.1111/ced.14277

17. Fernandez-Nieto D, Jimenez-Cauhe J, Suarez-Valle A, et al. Characterization of acute acral skin lesions in nonhospitalized patients: a case series of 132 patients during the COVID-19 outbreak. J Am Acad Dermatol. 2020;83:E61-E63. doi:10.1016/j.jaad.2020.04.093

18. Marzano AV, Genovese G, Fabbrocini G, et al. Varicella-like exanthem as a specific COVID-19-associated skin manifestation: Multicenter case series of 22 patients. J Am Acad Dermatol. 2020;83:280-285. doi:10.1016/j. jaad.2020.04.044

19. Fernandez-Nieto D, Ortega-Quijano D, Segurado-Miravalles G, et al. Comment on: cutaneous manifestations in COVID-19: a first perspective. safety concerns of clinical images and skin biopsies. J Eur Acad Dermatol Venereol. 2020;34:E252-E254. https://doi.org/10.1111/jdv.16470

20. Herrero-Moyano M, Capusan TM, Andreu-Barasoain M, et al. A clinicopathological study of eight patients with COVID-19 pneumonia and a lateonset exanthema. J Eur Acad Dermatol Venereol. 2020;34:E460-E464. https:// doi.org/10.1111/jdv.16631

21. Rubio-Muniz CA, Puerta-Peña M, Falkenhain-López D, et al. The broad spectrum of dermatological manifestations in COVID-19: clinical and histopathological features learned from a series of 34 cases. J Eur Acad Dermatol Venereol. 2020;34:E574-E576. https://doi.org/10.1111/ jdv.16734

22. Jimenez-Cauhe J, Ortega-Quijano D, Carretero-Barrio I, et al. Erythema multiforme-like eruption in patients with COVID-19 infection: clinical and histological findings. Clin Exp Dermatol. 2020;45:892-895. https://doi. org/10.1111/ced.14281 
23. Jimenez-Cauhe J, Ortega-Quijano D, de Perosanz-Lobo D, et al. Enanthem in patients with COVID-19 and skin rash. JAMA Dermatol. 2020;156:11341136. doi:10.1001/jamadermatol.2020.2550

24. Le Cleach L, Dousset L, Assier H, et al. Most chilblains observed during the COVID-19 outbreak occur in patients who are negative for COVID-19 on polymerase chain reaction and serology testing. $\mathrm{Br} \mathrm{J}$ Dermatol. 2020;183:866-874. https://doi.org/10.1111/bjd.19377

25. Hubiche T, Cardot-Leccia N, Le Duff F, et al. Clinical, laboratory, and interferon-alpha response characteristics of patients with chilblain-like lesions during the COVID-19 pandemic [published online November 25, 2020]. JAMA Dermatol. doi:10.1001/jamadermatol.2020.4324

26. Freeman EE, McMahon DE, Lipoff JB, et al. Pernio-like skin lesions associated with COVID-19: a case series of 318 patients from 8 countries. J Am Acad Dermatol. 2020;83:486-492. doi:10.1016/j.jaad.2020.05.109

27. Magro CM, Mulvey JJ, Laurence J, et al. The differing pathophysiologies that underlie COVID-19-associated perniosis and thrombotic retiform purpura: a case series. Br J Dermatol. 2021;184:141-150. https://doi.org/10.1111/ bjd.19415

28. Colmenero I, Santonja C, Alonso-Riaño M, et al. SARS-CoV-2 endothelial infection causes COVID-19 chilblains: histopathological, immunohistochemical and ultrastructural study of seven paediatric cases. Br J Dermatol. 2020;183:729-737. doi:10.1111/bjd.19327

29. Droesch C, Do MH, DeSancho M, et al. Livedoid and purpuric skin eruptions associated with coagulopathy in severe COVID-19. JAMA Dermatol. 2020;156:1-3. doi:10.1001/jamadermatol.2020.2800

30. Asakura H, Ogawa H. COVID-19-associated coagulopathy and disseminated intravascular coagulation. Int J Hematol. 2021;113:45-57. doi:10.1007/ s12185-020-03029-y

31. Dufort EM, Koumans EH, Chow EJ, et al. Multisystem inflammatory syndrome in children in New York State. N Engl J Med. 2020;383:347-358. doi:10.1056/NEJMoa2021756

32. Young TK, Shaw KS, Shah JK, et al. Mucocutaneous manifestations of multisystem inflammatory syndrome in children during the COVID-19 pandemic. JAMA Dermatol. 2021;157:207-212. doi:10.1001/jamadermatol.2020.4779

33. Whittaker E, Bamford A, Kenny J, et al. Clinical characteristics of 58 children with a pediatric inflammatory multisystem syndrome temporally associated with SARS-CoV-2. JAMA. 2020;324:259-269. doi:10.1001/jama.2020.10369

34. Cheng MH, Zhang S, Porritt RA, et al. Superantigenic character of an insert unique to SARS-CoV-2 spike supported by skewed TCR repertoire in patients with hyperinflammation. Proc Natl Acad Sci US A. 2020;117:2525425262. doi:10.1073/pnas.2010722117

35. Morris SB, Schwartz NG, Patel P, et al. Case series of multisystem inflammatory syndrome in adults associated with SARS-CoV-2 Infection-United Kingdom and United States, March-August 2020. MMWR Morb Mortal Wkly Rep. 2020;69:1450-1456. doi:10.15585/mmwr. mm6940e1

36. Blanco-Melo D, Nilsson-Payant BE, Liu W-C, et al. Imbalanced host response to SARS-CoV-2 drives development of COVID-19. Cell. 2020;181:1036.e9-1045.e9. doi:10.1016/j.cell.2020.04.026

37. Crow YJ, Manel N. Aicardi-Goutières syndrome and the type I interferonopathies. Nat Rev Immunol. 2015;15:429-440. doi:10.1038/nri3850

38. Hadjadj J, Yatim N, Barnabei L, et al. Impaired type I interferon activity and inflammatory responses in severe COVID-19 patients. Science. 2020;369:718-724. doi:10.1126/science.abc6027

39. Zimmermann $\mathrm{N}$, Wolf $\mathrm{C}$, Schwenke $\mathrm{R}$, et al. Assessment of clinical response to janus kinase inhibition in patients with familial chilblain lupus and TREX1 mutation. JAMA Dermatol. 2019;155:342-346. doi:10.1001/jamadermatol.2018.5077

40. Hubiche T, Le Duff F, Chiaverini C, et al. Negative SARS-CoV-2 PCR in patients with chilblain-like lesions. Lancet Infect Dis. 2021;21:315-316. doi:10.1016/S1473-3099(20)30518-1

41. Agrawal A. Mechanisms and implications of age-associated impaired innate interferon secretion by dendritic cells: a mini-review. Gerontology. 2013;59:421-426. doi:10.1159/000350536

42. Kalil AC, Patterson TF, Mehta AK, et al. Baricitinib plus remdesivir for hospitalized adults with COVID-19. N Engl J Med. 2021;384:795-807. doi:10.1056/NEJMoa2031994
43. US Food and Drug Administration. Fact sheet for healthcare providers: emergency use authorization (EUA) of baricitinib. Accessed March 29, 2021. https://www.fda.gov/media/143823/download

44. Konno Y, Kimura I, Uriu K, et al. SARS-CoV-2 ORF3b is a potent interferon antagonist whose activity is increased by a naturally occurring elongation variant. Cell Rep. 2020;32:108185. doi:10.1016/j.celrep.2020.108185

45. Sacks D, Baxter B, Campbell BCV, et al. Multisociety consensus quality improvement revised consensus statement for endovascular therapy of acute ischemic stroke: from the American Association of Neurological Surgeons (AANS), American Society of Neuroradiology (ASNR), Cardiovascular and Interventional Radiology Society of Europe (CIRSE), Canadian Interventional Radiology Association (CIRA), Congress of Neurological Surgeons (CNS), European Society of Minimally Invasive Neurological Therapy (ESMINT), European Society of Neuroradiology (ESNR), European Stroke Organization (ESO), Society for Cardiovascular Angiography and Interventions (SCAI), Society of Interventional Radiology (SIR), Society of NeuroInterventional Surgery (SNIS), and World Stroke Organization (WSO). J Vasc Interv Radiol. 2018;29:441-453. doi:10.1016/j. jvir.2017.11.026

46. Lo MW, Kemper C, Woodruff TM. COVID-19: complement, coagulation, and collateral damage. J Immunol. 2020;205:1488-1495. doi:10.4049/jimmunol.2000644

47. Magro C, Mulvey JJ, Berlin D, et al. Complement associated microvascular injury and thrombosis in the pathogenesis of severe COVID-19 infection: a report of five cases. Transl Res. 2020;220:1-13. doi:10.1016/j. trsl.2020.04.007

48. Yan B, Freiwald T, Chauss D, et al. SARS-CoV2 drives JAK1/2-dependent local and systemic complement hyper-activation [published online June 9, 2020]. Res Sq. doi:10.21203/rs.3.rs-33390/v1

49. Marietta M, Coluccio V, Luppi M. COVID-19, coagulopathy and venous thromboembolism: more questions than answers. Intern Emerg Med. 2020;15:1375-1387. doi:10.1007/s11739-020-02432-x

50. Zuo Y, Estes SK, Ali RA, et al. Prothrombotic antiphospholipid antibodies in COVID-19 [published online June 17, 2020]. medRxiv. doi:10.1101/2020.06.15.20131607

51. Lan S-H, Lai C-C, Huang H-T, et al. Tocilizumab for severe COVID-19: a systematic review and meta-analysis. Int J Antimicrob Agents. 2020;56:106103. doi:10.1016/j.jiantimicag.2020.106103

52. McMahon D, Gallman A, Hruza G, et al. COVID-19 "long-haulers" in dermatology? duration of dermatologic symptoms in an international registry from 39 countries. Abstract presented at: 29th EADV Congress; October 29, 2020. Accessed March 29, 2020. https://eadvdistribute .m-anage.com/from.storage?image=PXQEdDtIClihN3sM_8nAmh7p _y9AFijhQlf2-_KjrtYgOsOXNVwGxDdti95GZ2Yh0

53. Saag MS. Misguided use of hydroxychloroquine for COVID-19: the infusion of politics into science. JAMA. 2020;324:2161-2162. doi:10.1001/ jama.2020.22389

54. Zahedi Niaki O, Anadkat MJ, Chen ST, et al. Navigating immunosuppression in a pandemic: a guide for the dermatologist from the COVID Task Force of the Medical Dermatology Society and Society of Dermatology Hospitalists. J Am Acad Dermatol. 2020;83:1150-1159. doi:10.1016/j.jaad.2020.06.051

55. Hammond MI, Sharma TR, Cooper KD, et al. Conducting inpatient dermatology consultations and maintaining resident education in the COVID-19 telemedicine era. J Am Acad Dermatol. 2020;83:E317-E318. doi:10.1016/j.jaad.2020.07.008

56. Brunasso AMG, Massone C. Teledermatologic monitoring for chronic cutaneous autoimmune diseases with smartworking during COVID-19 emergency in a tertiary center in Italy. Dermatol Ther. 2020;33:E13495-E13495. doi:10.1111/dth.13695

57. Trinidad J, Kroshinsky D, Kaffenberger BH, et al. Telemedicine for inpatient dermatology consultations in response to the COVID-19 pandemic. J Am Acad Dermatol. 2020;83:E69-E71. doi:10.1016/j.jaad.2020.04.096

58. Madigan LM, Micheletti RG, Shinkai K. How dermatologists can learn and contribute at the leading edge of the COVID-19 global pandemic. JAMA Dermatology. 2020;156:733-734. doi:10.1001 /jamadermatol.2020.1438 